\title{
METHOD OF RESTORING MINE HOISTING MACHINE BRAKE UNIT LEVER TRANSMISSION BUSHING
}

\author{
Marat Ibatov $^{2}$, Ali Mekhtiyev ${ }^{1,2}$, Felix Bulatbayev ${ }^{2}$, Oxana Yakupova ${ }^{3 a}$ \\ ${ }^{1}$ National Research Tomsk Polytechnic University, 634050, Tomsk, Russia \\ ${ }^{2}$ Karaganda State Technical University, 100000, Karaganda, Kazakhstan \\ ${ }^{3}$ National Research Tomsk State University, 634050, Tomsk, Russia
}

\begin{abstract}
In the article results of researches of brake devices of lifting machines UD of joint-stock company "ArcelorMittal Temirtau" are resulted. Defects were revealed as a result of the examination. A method and device for the unconditional control of defects and technical condition of the hinged joints of brake devices is developed in terms of the gap size and the angle of rotation between the links of the kinematic pairs "Widget-finger". For the monitoring of gaps, capacitive sensors are installed, mounted on hinged joints. It is substantiated that with the use of capacitive sensors it is possible to control the gaps in the hinged joints in real time. A device has been developed that makes it possible to estimate the magnitude of the gap at several points of the kinematic chain of the mechanism simultaneously.
\end{abstract}

\section{Introduction}

One of the most important elements in the technological chain of mineral resources mining at mines id hoisting-transporting equipment. Intensification of stoping and preparatory operations requires continuous increasing of mine hoisting plants capacity and productivity. With productivity increasing there increases the significance of providing normative reliability, as in these conditions freight hoisting plants failures lead to the significant loss of mineral resources mining, man hoisting failures lead to the potential danger for peoples' life. Solving the problem of increasing the technical level, wear resistance and reliability of constructional parts of hoisting-transporting equipment is one of the main priorities of mining machine building development.

A brake unit is one of the most complicated and important units of a hoisting plant which is the final element in the protection means chain. The raised standards are claimed to it, as on its perfectness there depends reliability and safety of hoisting plant operation [1].

In the process of using hoisting plants there occur significant braking forces in the brake unit elements both in normal modes and in emergency situations with the hoisting vessel sudden stops in the shaft [2]. Hinges jamming or their excessive wear can become a cause of a serious accident. Brake system hinge joints are to be timely repaired.

\footnotetext{
a Corresponding author:1_neg@mail.ru
} 
Mine hoisting plant brake unit hinge joints wear can be a result of constructional characteristic features, contact surface material mechanical properties, manufacturing technology and quality, friction type, existing abrasive particles on the friction surface, use and mode of operation. To prevent untimely failures in brake units operation it is necessary still at the designing stage to take into consideration all the factors effecting hinge wear.

Meanwhile, there are not used the possibilities of ensuring the hinges rated reliability due to increasing the contact surface areas. Starting from the above-said, establishing hinge joints elements rational constructional parameters is an urgent problem. To solve this problem at the first stage it is necessary to determine stresses on the hinge coupling surface. Using imitation modeling, there was carried out the analysis of occurring contact stresses depending on bushings geometrical form and contact surface area.

\section{Experimental study}

There were studied typical hinges with cylindrical inner surface. Besides, there were suggested bushings with partially conical boring (with different ratios of the cylindrical and conical parts) and bushings with complete conical boring on the full length [3].

The experiment was carried out with five imitation models of hinges with different constructional parameters (Figure 1).

The imitation models have the following differences:

the first variant is a typical structure with the bushing cylindrical inner surface on AK line with diameter $\mathrm{d}_{2}$;

the second variant has a partial conical boring of the bushing inner surface for 0.1 of its length on $\mathrm{ABC}$ line with diameters $\mathrm{d}_{2}$ and $\mathrm{d}_{3}$;

the third variant has a partial conical boring of the bushing inner surface for 0.35 of its length on $\mathrm{ABC}$ lines with diameters $\mathrm{d}_{2}$ and $\mathrm{d}_{3}$;

the fourth variant has a partial conical boring of the bushing inner surface for 0.7 of its length on $\mathrm{ABC}$ line with diameters $\mathrm{d}_{2}$ and $\mathrm{d}_{3}$;

the fifth variant has a complete conical boring of the bushing inner surface for the full its length on AC line with diameters $\mathrm{d}_{2}$ and $\mathrm{d}_{3}$.

Due to the use of the conical surface there increases the bushing and the pin surface contact area and, as a result there reduce contact stresses in the operating condition and the bushing contact surface wear. Studying the imitation model of the "bushing-and-pin" pair using applied programs ANSYS package showed that external loads applying would change stress distribution in the zone subjected to wear.

There was experimentally established the dependence of stresses on the bushing contact surface on the boring depth relative to its general length. Due to the use of the conical surface there increases the contact area of the bushing and pin surfaces and as a result there reduce contact stresses in the operating condition. The geometrical sense of this phenomenon is demonstrated in Figure 1. The bushing wear reducing takes place due to the bushing contact area with the pin, as the contact area on the body surface with $A B C$ generatrix is larger than that on the surface with $\mathrm{AK}$ generatrix. The sum of $\mathrm{AB}$ and $\mathrm{BC}$ sides is larger than $\mathrm{AC}$ side, consequently, the genetratrix with $\mathrm{ABC}$ bend is more effective than $A C$ straight $L_{1}$ if the bushing length; $L_{2}$ is the bushing inner conical surface boring depth; $d_{1}$ id the bushing outside diameter; $d_{2}$ the bushing inner diameter; $d_{3}$ is the bushing larger inner diameter after boring; $\gamma$ is minimal possible thickness of the bushing wall from the condition of crush line. In designing $\mathrm{C}$ point is determined from the condition of the bushing crush condition. The inclination angle $\angle \mathrm{CBK}$ is to be larger than Morse cone angle (70). With the boring angles less than 70 there can occur the coupled surfaces catching and the hinge jamming [4]. 
The analysis of the obtained dependences of stresses on the bushing contact surfaces of various structures permitted to determine the rational form of the hinge bushing. The conical part boring depth makes $0.42 \ldots 0.64$ of the bushing general length.

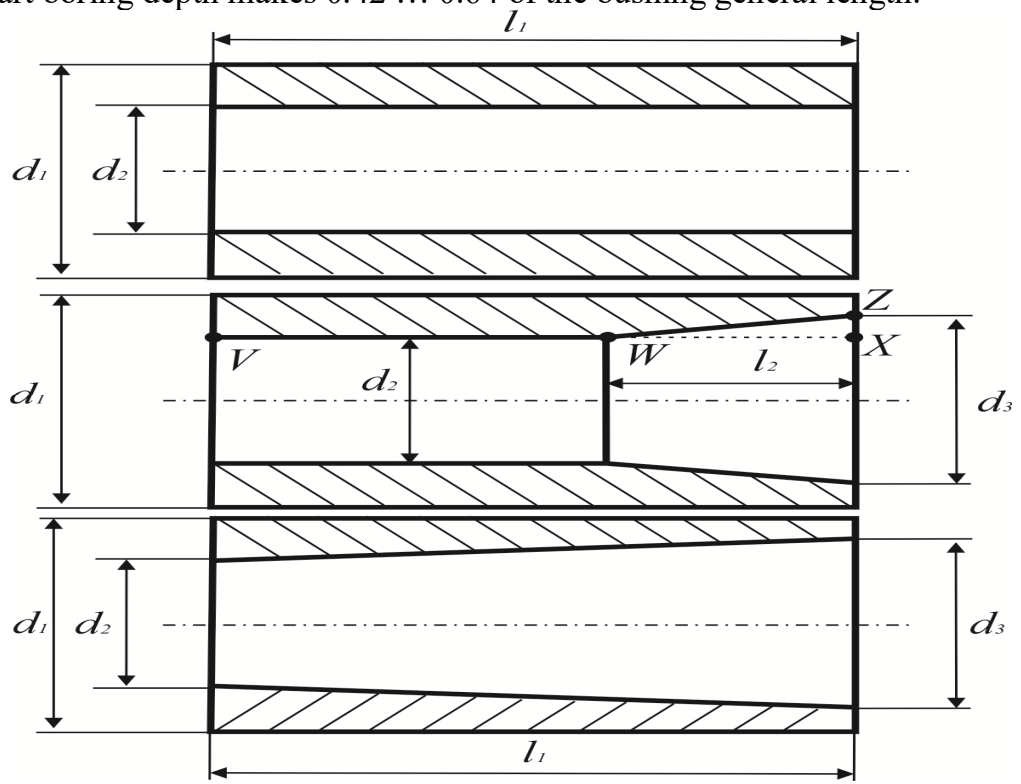

Fig. 1. Bushing longitudinal section: $l_{1}-$ length of the sleeve; $l_{2}-$ depth of boring of the inner conical surface of the bushing; $d_{1}-$ outer diameter of the bushing; $d_{2}-$ inner diameter of the bushing; $\mathrm{d}_{3}$-larger internal diameter of the bushing after boring.

The dependence on the voltage on the contact surface of the bushing of the drilling depth relative to its total length is presented in Figure 2.

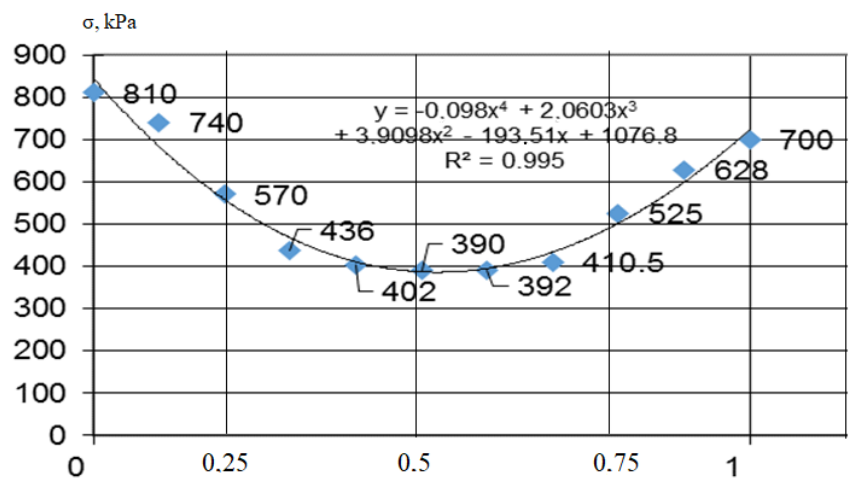

Fig. 2. Stress dependence on the bushing contact surface of the boring depth relative to its general length.

\section{Developed methods}

The aim of the developed method of hinge restoring is widening technological possibilities of repairing and increasing the operation resource of mine hoisting machine brake unit mechanism hinge joints $[5,6]$. 
The technical decision essence consists in the possibility to restore a hinge joint without complete dissembling mine hoisting machine brake unit mechanism.

There are known various methods of restoring mine hoisting machine brake unit mechanism hinge joints. These methods have the drawback in the necessity to disassemble the brake system mechanism in order to press in the bushes, the bush setting complexity, the necessity of the double boring before and after the bush setting. This is connected with certain technological difficulties, as there must be disassembled the brake mechanism elements and stopped the mine hoisting machine operation for a sufficiently long period.

Typical bushing-and-pin elements of the brake mechanism hinge joints has a relatively short service life because, as a result of wear there form inadmissible clearances in hinge joints elements $[2,7]$. It in turn leads to the impossibility to set normative clearances between the braking shoe and the braking rim of the rope winding element. Such state of the brake unit can lead to the mechanism jamming and damaging separate elements. To replace worn hinge joints with new ones there is performed the complete disassembling of the brake unit mechanism, the worn bushings removal and pressing in new bushings at workshops. As a result we have losses due to the hoisting-transport equipment downtime and expenses for its following adjustment.

The suggested method of repairing can be used for a typical structure of industrially manufactured bushing-and-pin elements of unit hinge joints for mine hoisting plants of NKMZ 2C-4x2.3; 2C-5x2.3; 2C-5x2.4 and 2C-6x2.4 types.

The studies showed that the main causes of the bushing-and-pin pair failure are the following factors: increasing clearances due to the bushing wear, limit contact stresses in the process of use, insufficiently effective distribution of lubricants over the contact surfaces. For the bushing manufacture there is used cast iron (SCh), for the pin - highcarbon steel of ST 45X grade. This pair possesses low wear resistance but here it is possible to use a worn bushing repeatedly within several inter-repair periods.

The developed method permits to reduce costs and time for the repair-and-restoration operations of mine hoisting machine brake unit mechanism. The hinge bushing restoring is performed without the complete disassembling of mine hoisting machine brake unit. The technology stipulates boring a cylindrical conical opening at the place of the bush setting using a mobile cutting tool. The bush opening boring along its geometrical axis is performed with a cylindrical and conical cutter. The bushing conical part makes 0.35 of the bushing full length. In the bored opening there is set a pin of corresponding configuration. It is economically expedient to use a bush in two repairing periods without its and the whole mechanism disassembling. In the repeated restoring the conical part is bored for 0.7 of the bushing total length. The conical form permits to increase the contact surfaces area, to exclude the radial skewing when setting a pin and to restrict the pin end travel in the bushing in the process of operation. This increases the brake unit mechanism hinge joint service life.

The method of restoring mine hoisting plant brake unit hinge joints is presented in Figure 3. 


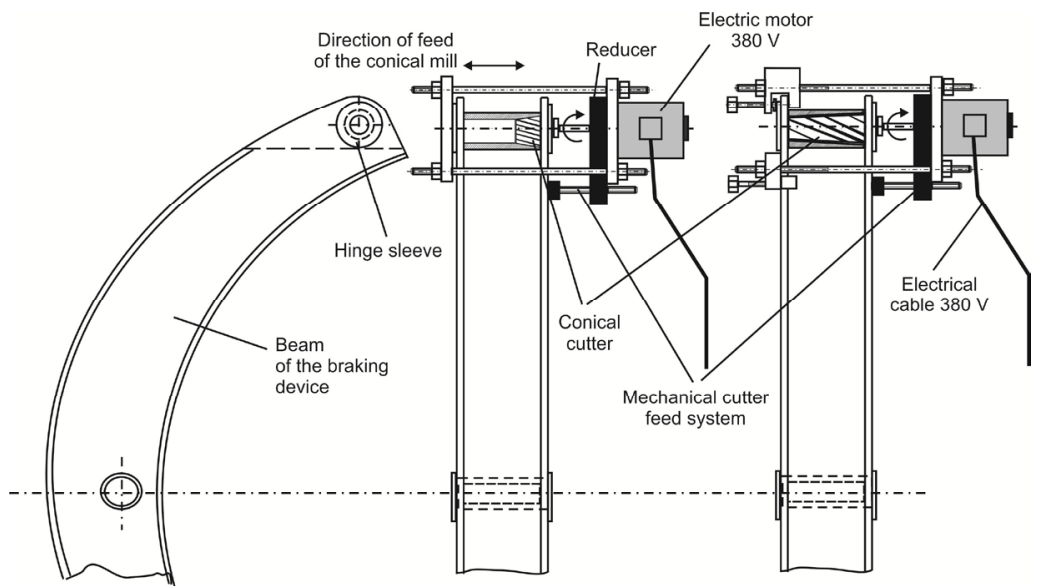

Fig. 3. Methods of fastening a mobile unit for hinge restoring.

When performing repair, the clearance value and the degree of the pair "bushing-andpin" wear are preset in advance. Experimental studies showed that uniform wear of the total lever transmission bushing surface is characteristic, and this leads to increasing a clearance between the pin and the bushing. This excess breaks the hinge normal work and requires replacing the bushing.

A hinge with the excess of the clearance admissible value is disassembled. Using a mobile cutting plant there is performed the boring of an opening with cutter $1_{1}$ of the cylindrical and then partly conical form. Guiding units 7 and pneumatic cylinder 4 provide the necessary travel of the boring unit working element whose rotation is carried out through reduction gear 10 from electric drive 9. To restore mine hoisting machine brake unit hinge bushings working surfaces and liquidation of the admissible clearance excess, there is performed boring to the first repair size. Let's make the primary measuring of diameters $d_{1} ; d_{2}$ and length $L_{1}$ (Figure 4 ). The boring depth of the bushing $L_{3}$ inner conical surface (Figure 5) is selected as a part of the total length $\mathrm{L}_{1}$ (conical part makes 0.35 of the bushing total length). The remaining part of $\mathrm{L}_{2}$ length is bored to the cylindrical form with the new opening diameter $d_{3}$ equal to $d_{2}+2 \Delta_{\text {wear }}\left(\Delta_{\text {wear }}\right.$ is the value of the bushing inner diameter radial wear). The boring angle is: $\operatorname{tg} \varphi=\delta / L_{3}$. The bushing larger inner diameter $d_{4}$ is determined from the condition of the bush crushing. The maximum angle of the bushing conical boring is restricted by its outer diameter. The minimum angle of the conical boring is restricted by the value 70 (Morse's cone). The link pin has the configuration similar to that of the bushing inner surface by the first repair size accounting allowances and fits [3].

After a certain period of operation between the working surfaces of the bushing and pin coupling there again forms a clearance affecting the mechanism normal operation. In this case it is possible to repeat the bushing inner surface restoration to the second repair size (the conical part makes 0.7 of the bushing total length), where diameter $d_{3}$ of the second repair size is equal to the sum of the first repair size cylindrical part and $2 \Delta$. 


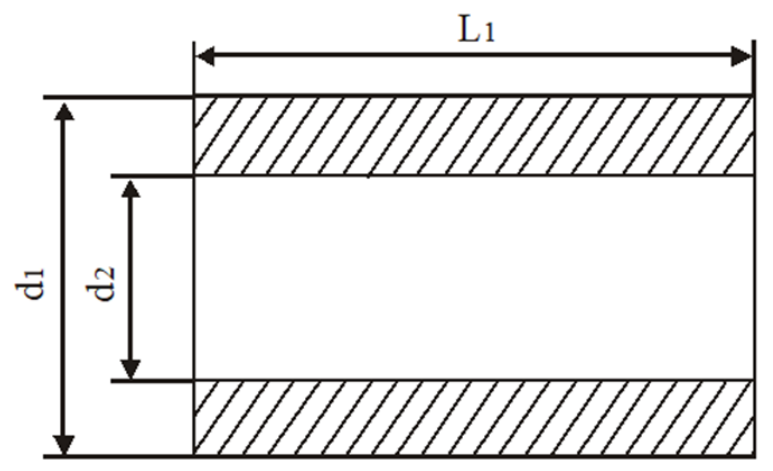

Fig. 4. Typical bushing structure.

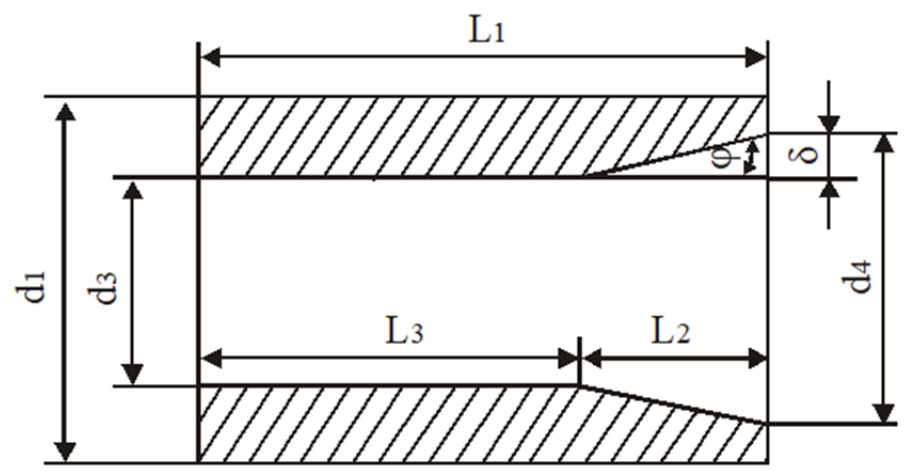

Fig. 5. The bushing structure with partial conical boring.

The conical form permits to exclude a radial skewing when assembling the pin and to restrict the ping travel in the bushing in the process of use. Taking into consideration the abovementioned, we can state the increase of the operation resource of mine hoisting machine brake unit hinge joint.

The results of theoretical and experimental studies were used in restoring the brake unit hinges on the hoisting machines of a drain well at LLP "Bogatyr Komir". The work was performed immediately on the hoisting plants within the periods of the equipment shortterm stops without dissembling the brake system mechanism. In total there were restored 30 bushings of hinge joints.

\section{Conclusion}

The carried out experimental studies of various hinge structures stressed-and-strained state (imitation modeling) permitted to determine parameters of the bushing inner surface boring with the least stress in the zone of the bushing and the pin contact. The bushing boring interval makes $0.42 \ldots 0.64$ of its full length. Increasing the bushing-and pin pair contact surfaces area due to the conical boring reduces the hinge joint wear.

\section{References}

[1] V.R. Bezhok, R.Ia. Gruzutin, V.G. Kalinin, B.N. Chaika, Neispravnosti shakhtnykh pod"emnykh ustanovok (Nedra, Moscow, 1991)

[2] A.D. Mekhtiyev, V.V. Yugai, Scientific-analytical and production journal "Mining 
equipment and electrical mechanics" 6, 26 (2011)

[3] F.N. Bulatbayev, A.D. Mekhtiyev, V.V. Likhachoyv, University proceedings 4, 50 (2011)

[4] A.V. Yurchenko, A.D. Mekhtiyev, F.N. Bulatbaev, Y.G. Neshina, A.D. Alkina and M.M. Kokkoz, Journal of Physics: Conference Series 881 (2017) doi: 10.1088/17426596/881/1/012034

[5] V.R. Bezhok, R.Ya. Gruzutin, V.G. Kalinin, B.N. Chaika, Mine hoisting plants failures (Nedra, Moscow, 1991)

[6] A.V. Yurchenko, A.D. Alkina, A.D. Mekhtiyev, F.N. Bulatbayev, E.G. Neshina, MATEC Web of Conferences 79, 01085 (2016)

[7] T. R. Muksunov, N. K. Maksimova, E. Yu. Sevast'yanov, S. É. Shipilov, V. P. Yakubov, Russian Physics Journal 57, 1287 (2015) 